\title{
Synthesis, characterization and application of a novel sorbent, glucamine-modified MCM-41, for the removal/preconcentration of boron from waters
}

\author{
Öznur Kaftan ${ }^{\text {a }}$, Müge Açıkel ${ }^{\text {a }}$, Ahmet E. Eroğlu ${ }^{\mathrm{a}, *}$, Talal Shahwan ${ }^{\mathrm{a}}$, \\ Levent Artok ${ }^{\mathrm{a}}$, Chaoying $\mathrm{Ni}^{\mathrm{b}}$ \\ a Department of Chemistry, İzmir Institute of Technology, 35430 Urla-i̇zmir, Turkey \\ b Department of Materials Science and Engineering, University of Delaware, Newark, DE 19716, USA
}

Received 30 October 2004; received in revised form 18 March 2005; accepted 21 March 2005 Available online 20 April 2005

\begin{abstract}
A novel sorbent was prepared by the functionalization of an inorganic support material, MCM-41, with $N$-methylglucamine for the uptake of boron from aqueous solutions prior to its determination by inductively coupled plasma optical emission spectrometry (ICP-OES). Characterization of the newly synthesized material was performed using BET, XRD, TEM, SEM and DRIFTS techniques, in addition to its $\mathrm{C}$ and $\mathrm{N}$ elemental content. Sorption behavior of the novel sorbent for boron was also investigated and found to obey Freundlich and Dubinin-Radushkevich (D-R) isotherm models. The maximum amount of $\mathrm{B}\left(\right.$ as $\mathrm{H}_{3} \mathrm{BO}_{3}$ ) that can be sorbed by the sorbent was calculated from the D-R isotherm and was found to be $0.8 \mathrm{mmol} \mathrm{B} \mathrm{g}^{-1}$ of sorbent. The applicability of the new sorbent for the removal/preconcentration of boron from aqueous samples was examined by batch method. It was found that the sorbent can take up $85 \%$ of boron in 5 min whereas quantitative sorption is obtained in $30 \mathrm{~min}$. Any $\mathrm{pH}$ greater than 6 can be used for sorption. Desorption from the sorbent was carried out using $1.0 \mathrm{M} \mathrm{HNO}_{3}$. The sorption efficiency of the new sorbent was also compared to that of Amberlite IRA 743, a commercial resin with $\mathrm{N}$-methylglucamine functional groups. Within the experimental conditions employed, the new sorbent was found to have higher sorption efficiency than the commercial resin. For method validation, spike recovery tests were performed at various concentration levels in different water types and were found to be between $83-95$ and $75-92 \%$ for ultra pure water and geothermal water, respectively.
\end{abstract}

(C) 2005 Elsevier B.V. All rights reserved.

Keywords: Boron; Inductively coupled plasma optical emission spectrometry; ICP-OES; Functionalization; MCM-41; $N$-methylglucamine; Amberlite IRA 743

\section{Introduction}

Boron is widely distributed in the environment, from natural or anthropogenic sources. It can be found mainly in the form of boric acid or borate salts. When the acid dissociation constant of boric acid $\left(5.81 \times 10^{-10}\right.$ at $\left.25^{\circ} \mathrm{C} ; \mathrm{p} K_{\mathrm{a}}=9.24\right)$ is considered, it can be predicted that $\mathrm{H}_{3} \mathrm{BO}_{3}$ is the predominant form at neutral and low $\mathrm{pHs}$ whereas $\mathrm{B}(\mathrm{OH})_{4}{ }^{-}$is expected to be present at high $\mathrm{pHs}$. Both forms may exist in equilibrium at a $\mathrm{pH}$ range of 7.0-11.5 [1]. At physiological pHs, the undis-

\footnotetext{
* Corresponding author. Tel.: +90 232 7507533; fax: +90 2327507509.

E-mail address: ahmeteroglu@ iyte.edu.tr (A.E. Eroğlu).
}

sociated form, $\mathrm{H}_{3} \mathrm{BO}_{3}$, is predominant. It has been reported that the conversion into undissociated form applies also to boric oxide and the sodium borates; as a consequence, the ecotoxicology of all these substances is likely to be similar to the case of boric acid [2].

Boron is an important micronutrient for plants, animals and humans, but it can be toxic at high concentrations. In recent years the use of boron compounds in metallurgy, microelectronics, glass products and in fertilizers has been increasing; so that boron compounds are released into the environment from these sources [3].

Sah and Brown reviewed the analytical methods for the determination of boron in different types of samples, 
indicating that the most common ones used are the spectrophotometric methods [4]. These methods have been reported to suffer from several methodological problems and are not adequately sensitive for some water samples that are naturally low in boron concentration.

Among the atomic spectroscopic methods, inductively coupled plasma optical emission spectrometry (ICP-OES) and electrothermal atomic absorption spectrometry (ETAAS) are used most frequently, although they suffer from interferences, memory effects and insufficient sensitivity for the determination of low levels of boron [5]. The generation of volatile species such as boron fluoride or methoxyborate and their introduction into the plasma appear to be a good approach to eliminate for example the spectral interference by the iron emission line in solution analysis by ICP-OES [6]. ICP mass spectrometry (ICP-MS) offers higher sensitivity, lower detection limits, and simultaneous measurement of total boron concentration and boron isotope ratios for biological tracer studies in the same run [4,7]. It has been mentioned that a special attention must be given to sample dissolution step because even small particles may clog the capillary tube to the nebulizer $[5,7,8]$.

Although boron and boron compounds are widely distributed in nature, their concentrations are generally low in most of the surface and ground waters, except those in the vicinity of borate mines or some industrial discharges. These low concentrations necessitate either the use of very sensitive analytical techniques or the application of suitable preconcentration methods prior to instrumental determination.

Some sample matrices can be problematic in boron determination. High salt concentration may affect the boron signals in many detection systems, whereas the presence of $\mathrm{Fe}$ in the sample solution (e.g., soil extracts, iron metal extracts, biological fluids, etc.) has been reported to cause spectral interference especially in ICP-OES determinations [4]. For these types of samples, there is a need to apply a matrix separation step prior to instrumental determination.

It is known that chelating resins containing functional groups in which hydroxyl groups are in the 1-2 or 1-3 positions show high selectivity for boron, as reported through the formation of borate-diol complexes $[9,10]$. There are also some other boron removal methods but ion exchange process is the most extensively used with some commercial boron selective resins, such as Amberlite XE 243 [9,11,12], the macroreticular resin Amberlite IRA743 [13,14] and some other $N$-methylglucamine type chelating resins, Diaion CRB01, Diaion CRB 02 and Purolite S 108 [15].

Due to high boron content of its wastewater, DenizliKizıldere geothermal field in Turkey has been the subject of some boron removal studies. The water disposed away from a power plant in this field has a capacity of $1500 \mathrm{th}^{-1}$ and contains boron at an approximate concentration of $30 \mathrm{mg} \mathrm{l}^{-1}$. When the average level of boron in irrigation waters (generally given as $1 \mathrm{mgl}^{-1}$ ) is considered, the very high level of boron in the disposed water of Kizıldere makes the use of this water for irrigation purposes impossible. For the investigation of boron removal from K1zildere geothermal wastewater, Amberlite IRA 743 [14], Diaion CRB 01, Diaion CRB 02, and Purolite S 108 [15] were employed. These resins have common in $N$-methylglucamine functional group and they just differ in the type of polymer chain and in some of their physical characteristics.

It has been recognized that borate ion is complexed by sorbitol groups, and a proton is retained by a tertiary amine site that behaves as a weakly basic anion exchanger, as outlined in Scheme 1 [16].

Various synthesis procedures can be found in literature for developing new resins for boron removal. For instance, Bicak et al. [17] synthesized a boron-specific resin by modification of crosslinked glycidyl methacrylate-based polymers. Inukai et al. [18] synthesized resins for boron sorption with natural organic polymer support cellulose. These studies include the functionalization of the polymer chain with the boronbinding group $N$-methylglucamine. In addition to the use of organic polymers, the functionalization can be realized by using an inorganic support material. Silica gel is one of the most widely used materials for this purpose as being an amorphous inorganic polymer with siloxane groups $(\mathrm{Si}-\mathrm{O}-\mathrm{Si})$ in the inward region and silanol groups $(\mathrm{Si}-\mathrm{OH})$ distributed on the surface. In recent years, modification of silica by inorganic or organic functional groups has been the subject of considerable interest due to many possibilities of application. Surface modifications are usually achieved with silylation using an appropriate organosilane reagent [19-22]. Modification of silica surface has also been the subject of a book [23].

In 1992, researchers of Mobil Inc. discovered the ordered mesoporous silicas, designated as micelle-templated silicas (MTS), which show a regularly ordered pore arrangement and very narrow pore size distribution [24,25]. One of the members of this material type, named MCM-41, has a

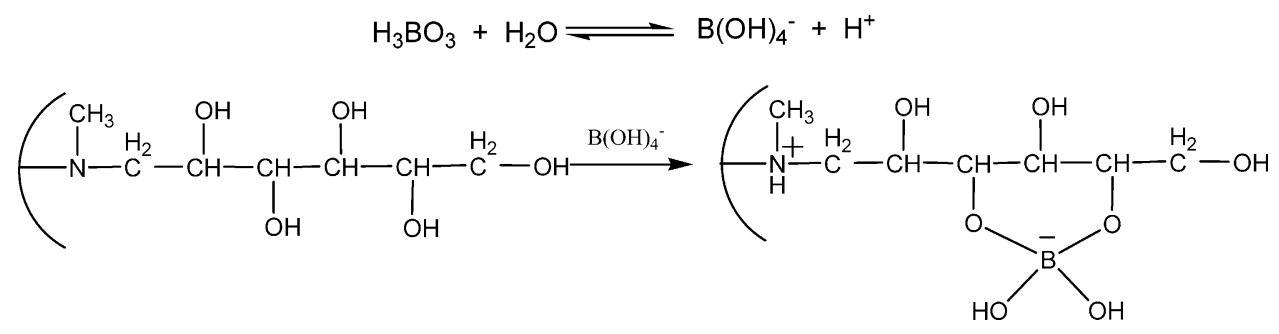

Scheme 1. The proposed mechanism for the sorption of boron by glucamine-functionalized sorbents [16]. 
one-dimensional, hexagonally ordered pore structure whereas the other member, MCM-48, is cubic ordered. These mesoporous materials with regular pore structure have pore diameters in the range from 2 to $10 \mathrm{~nm}$. Due to their high surface area and regular mesoporous system of pore mono-dispersed size, MTS have been reported to constitute an efficient mineral supports for the preparation of inorganicorganic hybrid materials by grafting organic chains onto their surface through silylation.

Various types of functional groups and molecules were incorporated into mesoporous materials mostly for catalytic applications. These studies have been widely revised by Moller and Bein [26]. Organic functionalization of the internal surface of a MTS host by covalently grafting various organic species into the channel walls, a post synthesis grafting process, has been widely employed to anchor specific organic groups onto surface silanols, typically using organochlorosilanes or organoalkoxysilanes as precursors for the surface modifications [26-33].

Surface modification of these materials by functionalization with organic groups permits the utilization for numerous potential applications, such as ion exchange, encapsulation of transition-metal complexes or semiconductor clusters, chemical sensing, adsorption and nano-material fabrication [27,34-40].

In this context our goal was to develop a novel sorbent material for preconcentration and matrix removal applications of B-containing water samples. For this purpose, a silicious MCM-41 was functionalized with $N$-methylglucamine and the new sorbent prepared was tested for its efficiency in boron sorption from aqueous solutions.

\section{Experimental}

\subsection{Instrumentation}

A Varian Liberty Series II Axial view ICP-OES was used in boron determinations in the liquid samples. The instrument was operated with the following conditions; incident power of $1.2 \mathrm{~kW}$, plasma gas flow rate of $151 \mathrm{~min}^{-1}$ and auxiliary gas flow rate of $1.51 \mathrm{~min}^{-1}$. Continuous nebulization was realized by means of a concentric glass nebulizer with cyclonic chamber. Measurements were based on peak height with polynomial plotted background correction method. The most sensitive emission lines of boron, 249.773 and $249.678 \mathrm{~nm}$, were chosen. In addition, $208.959 \mathrm{~nm}$ B line was monitored in case Fe interferes. The most sensitive B signal was obtained at $249.773 \mathrm{~nm}$ and thus all quantifications were conducted with the results obtained at this wavelength. Nevertheless, all three wavelengths were continued to be measured for check.

As it is known, one of the most important drawbacks of boron determination by ICP methods is the memory effect and this effect should be minimized in order to obtain reliable results. In the present study, mannitol-ammonia mixture, with the respective concentrations of $0.25 \%(\mathrm{w} / \mathrm{v})$ and $0.1 \mathrm{M}$, was used for both diluent and flush solutions as suggested by Sun et al. [41].

\subsection{Reagents}

All reagents were of analytical grade and used without further purification. Ultra pure water (18 M $\Omega$ ) was used throughout the study. All aqueous solutions prepared were stored in polyethylene/polypropylene containers. Plastic ware was cleaned by soaking them in approximately 1.5 $\mathrm{M}$ nitric acid and rinsed with ultra pure water prior to use. The boron stock standard solution was prepared by dissolving 5.716 g anhydrous $\mathrm{H}_{3} \mathrm{BO}_{3}$ (Carlo Erba 99.5-100\%, product code: 302177, CAS no: [10043-35-3]) in sufficient amount of ultra pure water and diluted to 11 . Sodium silicate $\left(27 \% \mathrm{SiO}_{2}-10 \% \mathrm{NaOH}\right.$, Riedel-de Haën, product code: 13729, CAS no: [1344-09-8]) was used as the silica source for the synthesis of support material MCM-41, and cetyltrimethylammonium bromide (CTMAB, Merck, product code: 1.023042, CAS no: [57-09-0]), a quaternary ammonium surfactant, for the synthesis of support material MCM-41. (3-Bromopropyl)trimethoxysilane (Fluka, product code:18262, CAS no: [13883-39-1]) and $N$-methylglucamine (Merck, product code: 818318 , CAS no: [6284-40-8]) were used in the surface modification of MCM-41. Amberlite IRA 743 (Aldrich, product code: 21,644-5, CAS no: [81133-21$3]$ ) was used for the check/comparison of the efficiency of newly developed sorbent. It is a commercial resin for boron sorption having macroporous polystyrene matrix with $N$ methylglucamine functional groups. Total capacity of the resin is given as 0.8 equiv. $1^{-1}$. The particle size of Amberlite IRA 743 was between 297 and $1190 \mu \mathrm{m}$ (50-16 mesh). However, in the sorption experiments, both the original and the ground resin $(53-75 \mu \mathrm{m})$ were used.

\subsection{Synthesis of $M C M-41$}

The synthesis of pure-silica MCM-41 was carried out by a delayed neutralization process proposed by Lin et al. [42] where cetyltrimethylammonium bromide (CTMAB) was used as the template. The synthesis was performed at $50{ }^{\circ} \mathrm{C}$ with a composition of $1 \mathrm{SiO}_{2}: 0.45$ surfactant:0.39 $\mathrm{Na}_{2} \mathrm{O}: 0.29 \mathrm{H}_{2} \mathrm{SO}_{4}: 50 \mathrm{H}_{2} \mathrm{O}$. Particle size of MCM-41 ranged between 1 and $7 \mu \mathrm{m}$ with an average value of $2.5 \mu \mathrm{m}$ as determined from the curve of cumulative particle size distribution.

\subsection{Functionalization of the MCM-41 surface}

The novel sorbent material was synthesized in two steps: in the first step the support material MCM-41 was functionalized with propyl bromide. In the subsequent step the grafted MCM-41 was reacted with $N$-methylglucamine to produce tertiary amine functionality to the material (Scheme 2).

Propyl bromide functionalization of MCM-41 was performed by refluxing $3 \mathrm{~g}$ of MCM-41 (freshly evacuated at $120{ }^{\circ} \mathrm{C}$ for $16 \mathrm{~h}$ ) in $50 \mathrm{ml}$ of dry $\mathrm{CHCl}_{3}$ solution of (3- 


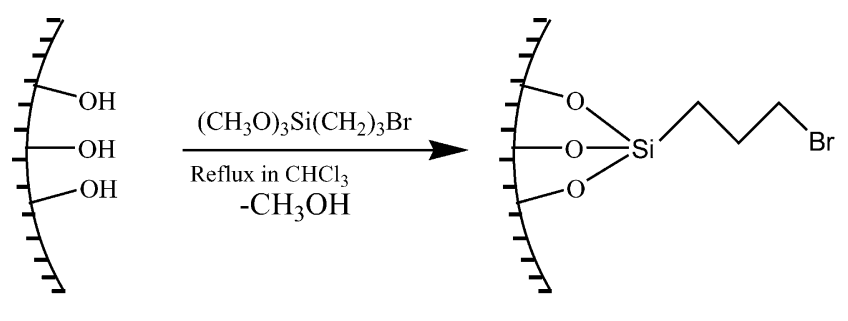

MCM-41

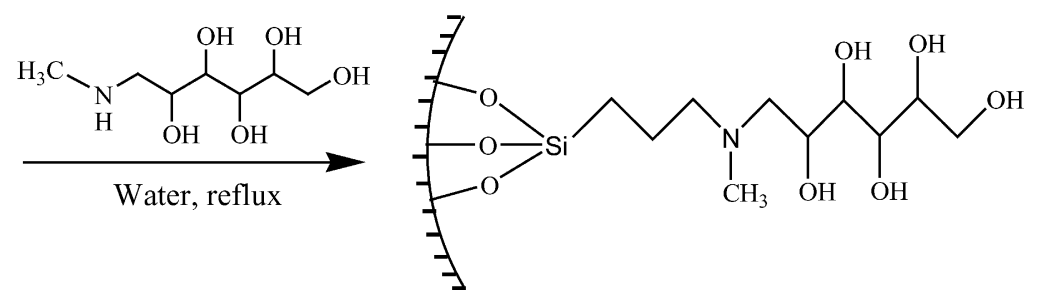

Scheme 2. Glucamine modification of MCM-41.

bromopropyl)trimethoxysilane (BPTMS) overnight under Ar atmosphere. Four different functionalized MCM-41 samples were prepared by varying the initial amount of BPTMS in the reaction medium as $0.5,1.0,1.5$, and $10 \mathrm{mmol} \mathrm{g}^{-1}$. The functionalized materials were then filtered and soxhletextracted with diethyl ether-dichloromethane mixture $(1: 1)$ for $12 \mathrm{~h}$. MCM-41 samples functionalized with the abovementioned amounts of propyl bromide were treated with $\mathrm{N}$-methylglucamine in refluxing water $(30 \mathrm{ml})$ for $16 \mathrm{~h}$ to produce $N$-methyl- $N$-propylglucamine functionality tethered onto the surface of MCM-41. In each case, the molar amount of $N$-methylglucamine used was three-fold higher than that of BPTMS used in grafting MCM-41. These glucaminefunctionalized MCM-41 samples were assigned as NMG$\operatorname{MCM}-41(n)$ where $n$ stands for numbers from 1 to 4 in order of increasing glucamine functionality. The modified sample was soxhlet-extracted with water for $16 \mathrm{~h}$. A more detailed explanation can be found in Table 1 .

\subsection{Characterization of the synthesized sorbent}

A number of characterization studies were employed to understand whether the functionalization of the MCM-41 surface was succeeded and then whether the framework of
MCM-41 support collapsed during the functionalization reactions. Characterization of the sorbents was carried out by means of transmission electron microscopy (TEM), X-ray diffraction (XRD), diffuse reflectance infrared Fourier transform spectrometry (DRIFTS), BET techniques and elemental analysis.

XRD data were collected on a Philips X'Pert Pro diffractometer using $\mathrm{Cu} \mathrm{K} \alpha$ radiation $(\lambda=0.154 \mathrm{~nm})$. Samples were introduced after compressing in the cassette sample holder without any adhesive substance.

DRIFTS measurements were carried out using Nicolet Magna 550 FTIR spectrometer equipped with Spectra-Tech Collector II model 0030-0XX diffuse reflectance accessory. The spectra were collected at a resolution of $8 \mathrm{~cm}^{-1}$ and averaged over 32 scans. In a typical measurement, $1 \mathrm{mg}$ of sample was mixed with and completely dispersed in $10 \mathrm{mg} \mathrm{KBr}$.

Elemental analysis of samples was carried out by Ankara Test and Analysis Laboratories of the Scientific and Technical Research Council of Turkey (TÜBİTAK) by using a LECO CHNS 932 elemental analyzer.

Specific surface area of the synthesized sorbents and the pure support material were measured using a static process by means of a Micrometrics ASAP 2010 instrument using nitrogen at $77 \mathrm{~K}$. The specific surface area was calculated by

Table 1

Elemental analysis results of $N$-methylglucamine-functionalized MCM-41 samples ${ }^{\mathrm{a}}$

\begin{tabular}{|c|c|c|c|c|c|}
\hline Sample & $\begin{array}{l}\text { Propyl bromide added } \\
\left(\mathrm{mmol} \mathrm{g}^{-1}\right)^{\mathrm{b}}\end{array}$ & $\begin{array}{l}\text { NMG added } \\
\left(\mathrm{mmol} \mathrm{g}^{-1}\right)^{\mathrm{c}}\end{array}$ & $\mathrm{C} \%$ & $\% \mathrm{~N}$ & $\begin{array}{l}\text { Amount of glucamine functionalized } \\
\left(\mathrm{mmol} \mathrm{g}^{-1} \text { sample }\right)^{\mathrm{d}}\end{array}$ \\
\hline NMG-MCM-41(1) & 0.5 & 1.5 & 4.80 & 0.55 & 0.39 \\
\hline NMG-MCM-41(2) & 1.0 & 3.0 & 6.85 & 0.69 & 0.49 \\
\hline NMG-MCM-41(3) & 1.5 & 4.5 & 9.97 & 1.02 & 0.73 \\
\hline NMG-MCM-41(4) & 10.0 & 30.0 & 13.62 & 1.42 & 1.01 \\
\hline
\end{tabular}

\footnotetext{
a Starting amount of MCM-41 was $3.0 \mathrm{~g}$ in each case.

b Amount of (3-bromopropyl)trimethoxysilane used in grafting MCM-41.

c Amount of $N$-methylglucamine used in functionalization of propyl bromide-grafted MCM- 41 .

d Calculated from $\mathrm{N}$ content of the samples.
} 
the BET method and average pore diameters and pore size distributions were calculated from the adsorption branch of the isotherm using the Barrett, Joyner and Helenda (BJH) method. All samples were degassed for $3 \mathrm{~h}$ at $423 \mathrm{~K}$.

SEM characterization was performed using a Philips XL30S FEG type instrument. Prior to analysis, the solid samples were sprinkled onto adhesive aluminium tapes supported on metallic disks. Microimages were then recorded at different magnifications.

For TEM analysis, the sample powders were dispersed in ethanol, and a drop of the solution was placed on Lacey carbon grid for drying in ambient environment. TEM observation was performed utilizing a Tecnai $\mathrm{G}^{2} 12$ transmission electron microscope operated at $120 \mathrm{kV}$. A Gatan MultiScan $600 \mathrm{CW}$ low dose CCD camera was used to record TEM images.

\subsection{Typical procedure for boron sorption studies}

In boron sorption studies, prescribed amount of sorbent was added into $20.0 \mathrm{ml}$ aqueous solution of $9.25 \times 10^{-4} \mathrm{M}$ $\mathrm{H}_{3} \mathrm{BO}_{3}$ (corresponding to $10.0 \mathrm{mg} \mathrm{l}^{-1} \mathrm{~B}$ ). The mixture was shaken manually for 1-2 min and then placed on a shaker for $30 \mathrm{~min}$. The contents were filtered through filter paper and the filtrate, after addition of the required amounts of $\mathrm{NH}_{3}$ and mannitol to have the respective concentrations of $0.1 \mathrm{M}$ and $0.25 \%(\mathrm{w} / \mathrm{v})$ [41], was analyzed by ICP-OES for boron determination.

\subsection{Desorption of boron from the sorbent}

After uptake of boron by the sorbent, its desorption was investigated using several acids such as $\mathrm{HNO}_{3}, \mathrm{H}_{2} \mathrm{SO}_{4}$ and $\mathrm{HCl}$ at 1.0 and $2.0 \mathrm{M}$ concentrations. For this purpose, the sorbent was taken into the eluents and was shaken once again for $30 \mathrm{~min}$ for desorption. At the end of this period, the solution was filtered and the filtrate was analyzed for its boron content.

\section{Results and discussion}

\subsection{Characterization of the synthesized sorbent}

The DRIFTS spectra of $N$-methylglucamine reagent, the unmodified MCM-41 and its modified samples were compared (not shown here) and the characteristic peaks at about 2950 and $1450 \mathrm{~cm}^{-1}$ were thought to be the demonstration of the success of the functionalization processes.

The functionalization capacity of the modified MCM-41 samples was estimated from their nitrogen content and was found to differ between 0.39 and $1.01 \mathrm{mmol}$ glucamine functionality per gram of sample (Table 1).

Nitrogen sorption isotherm is an efficient way for providing information about the pore system of materials. It is expected that the isotherms show gradual changes at each stage of modification as the organic fragments enter the channels (Fig. 1a). The BET surface area of the calcined MCM-41 was determined to be $1755 \mathrm{~m}^{2} \mathrm{~g}^{-1}$ and was then reduced to $767 \mathrm{~m}^{2} \mathrm{~g}^{-1}$ upon treatment with $1.5 \mathrm{mmol} \mathrm{g}^{-1}$ BPTMS. After functionalization with $N$-methylglucamine (NMG-MCM$41(3))$ the surface area was further reduced to $250 \mathrm{~m}^{2} \mathrm{~g}^{-1}$. As shown in Fig. 1b, the pore size distribution of the samples changed during grafting with BPTMS and also upon functionalization with $N$-methylglucamine. The mesoporous MCM-41 had an average pore size of $25.6 \AA$ whereas the pore size of propyl bromide-grafted MCM-41 was <20 (in the borderline between mesoporous and microporous structures). However, the $N$-methylglucamine-functionalized material (NMG-MCM-41(3)) was completely microporous $(\ll 20 \AA)$.

The TEM images of the synthesized and calcined MCM41 samples show that the pore channels were well developed long range order of hexagonal structures (Fig. 2a) and the samples preserved their integrity after propyl bromide functionalization (Fig. 2b). Although $N$-methylglucaminefunctionalized sample (NMG-MCM-41(3)) also exhibited hexagonal array of pore structure, it had uneven wall structures in some regions and elongation of the channel walls were interrupted due to the collapse of channel walls (Fig. 2c).
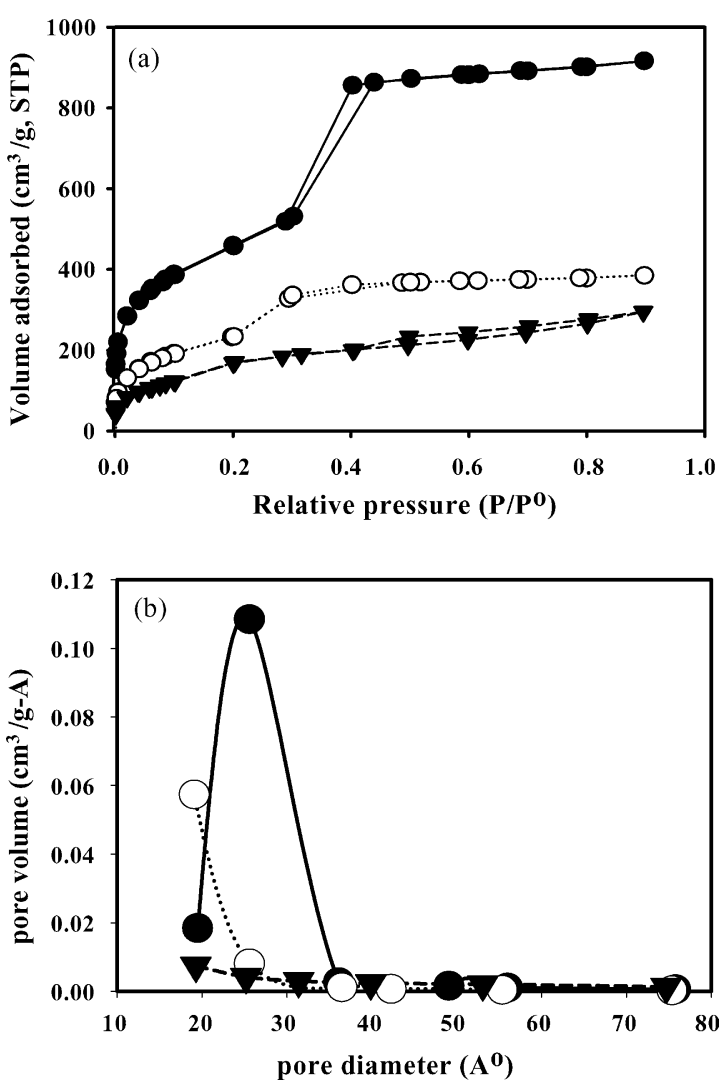

Fig. 1. (a) $\mathrm{N}_{2}$ adsorption-desorption isotherms and (b) pore size distribution of $(\mathbf{)})$ MCM-41, $(\bigcirc)$ propyl bromide-MCM-41, and $(\boldsymbol{\nabla})$ NMG-MCM41(3). 

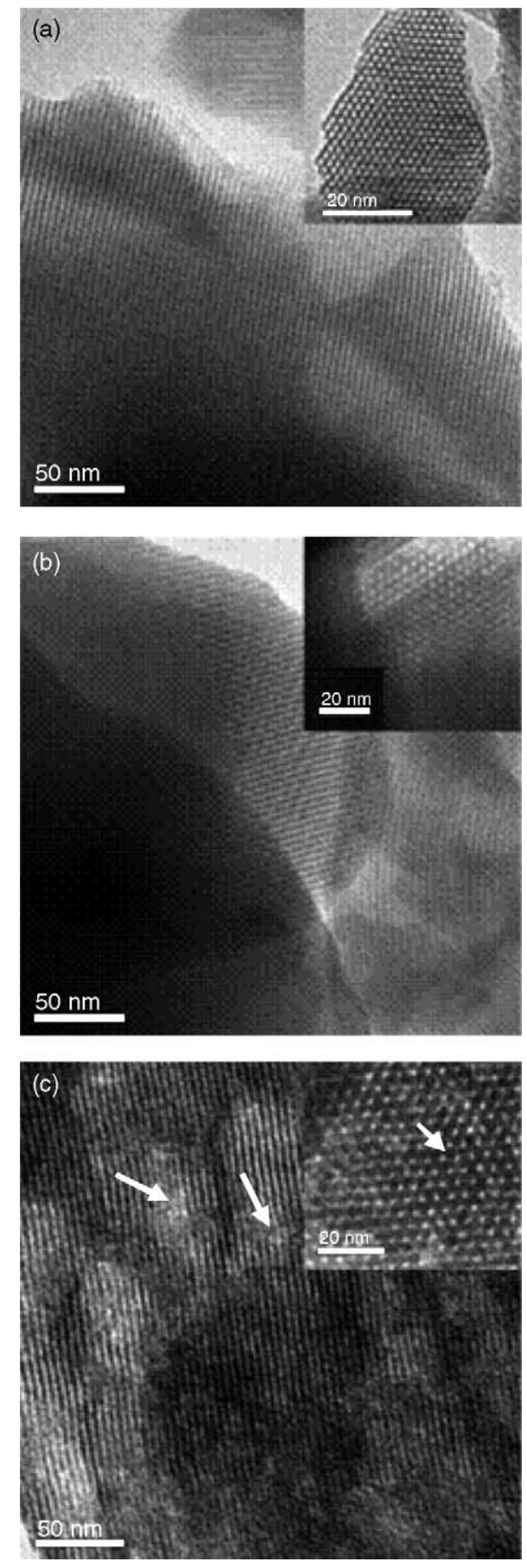

Fig. 2. TEM images of (a) MCM-41, (b) propyl bromide-MCM-41, (c) NMG-MCM-41(3). Arrows indicate wall defects.

The XRD pattern of synthesized MCM-41 showed an intense peak at a $2 \theta$ value of $2.3^{\circ}(100)$ and low intensity peaks between $3^{\circ}$ and $6^{\circ}$ which are characteristic of the long range hexagonal structure of MCM-41 (Fig. 3a). There appeared a decrease in overall intensities of XRD reflections of MCM-41 after propyl bromide functionalization (Fig. 3b). This may be due to the difference of scattering contrast between the amorphous silicate framework and organic moieties which are located inside the channels

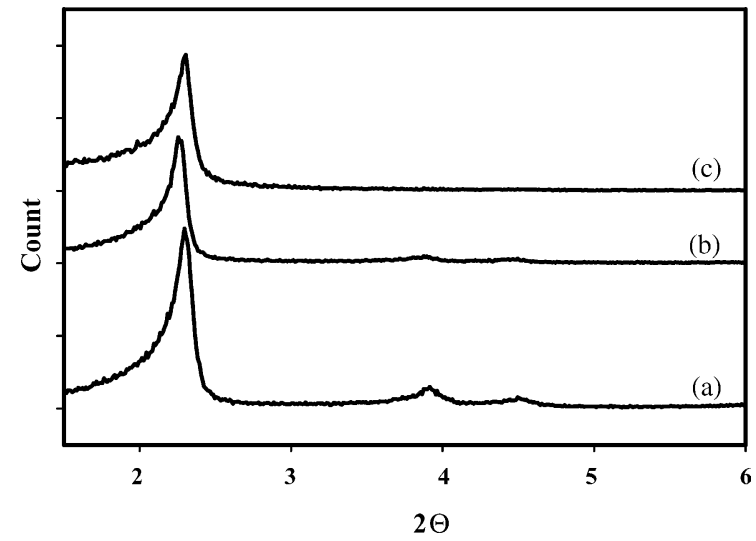

Fig. 3. XRD patterns of (a) MCM-41, (b) propyl bromide-MCM-41 and (c) NMG-MCM-41(3).

of MCM-41 [32,43]. N-methylglucamine functionalization (NMG-MCM-41(3)) caused the disappearance of low intensity peaks, while there appears only a slight change in the intensity of (100) reflection as compared with that of propyl bromide-grafted MCM-41 (Fig. 3c). The change in $d_{100}$ spacing values was negligible, varying between 38.3 and $39.1 \AA$. This observation is in agreement with the TEM images that demonstrated some defects in regularity of hexagonal pores of the sample upon glucamine functionalization. It must also be noted that the $\mathrm{pH}$ of the boiling solution was 11 during $N$-methylglucamine functionalization. It is well documented that the crystalline structure of MCM-41 collapses during treatment in basic aqueous solutions [44]. Yet, the glucamine functionalized MCM-41 sample possessed organized pore structure, though with the reduced quality. It was reported that the surface silylation improves the stability of MTS materials in water as a result of the increase in hydrophobicity [45-47]. In the same manner, the silylated structure should be more resistant towards base attack [48].

\subsection{The sorbent efficiency in boron sorption}

The MCM-41 samples funtionalized with different amounts of $N$-methylglucamine (as given in Table 1) were tested for their boron sorption efficiency. As can be seen from Fig. 4, the sorption capacity of the material increased dramatically until $\mathrm{N}$-methylglucamine content of the samples increased to $0.73 \mathrm{mmol} \mathrm{g}^{-1}$ (NMG-MCM-41(3)). However, the further increase in $N$-methylglucamine content (1.01 mmol g ${ }^{-1}$, NMG-MCM-41(4)) had a very little enhancement in the sorption capacity of the sorbent. Hence, for economy, NMG-MCM-41(3) was used in the subsequent investigations.

It was also determined that the unmodified MCM-41 and propyl bromide-functionalized MCM-41 (treated with $1.5 \mathrm{mmol} \mathrm{g}^{-1}$ BPTMS) had very little boron adsorption capacity $(9.2 \pm 0.2$ and $11.1 \pm 0.3 \%$, respectively, for $0.1 \mathrm{~g}$ of sample) as compared to the glucamine-funtionalized sorbents. 


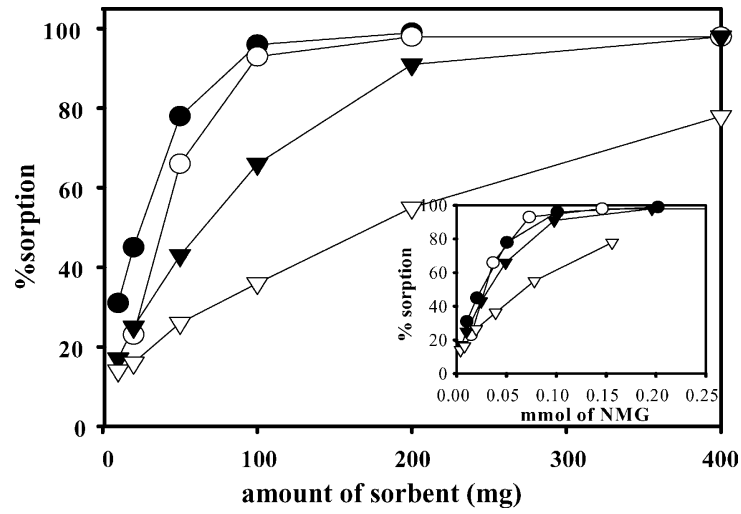

Fig. 4. Percent sorption capacity of the glucamine-functionalized MCM-41 sorbents (NMG-MCM-41(n)) as a function of sorbent amount $(\triangle) n=1,(\boldsymbol{\nabla})$ $n=2$, (○) $n=3,(\circlearrowleft) n=4$. Inset: Percent sorption capacity of the NMGMCM-41(n) as a function of mmol of $N$-methylglucamine (boron concentration: $10.0 \mathrm{mg} \mathrm{l}^{-1}$, solution volume: $20.0 \mathrm{ml}$ ).

\subsection{Effect of $\mathrm{pH}$ on sorption}

The form of boron in solution depends strongly on the $\mathrm{pH}$ and takes the forms of $\mathrm{B}(\mathrm{OH})_{3}$ at low $\mathrm{pHs}$ or $\mathrm{B}(\mathrm{OH})_{4}{ }^{-}$at high $\mathrm{pHs}$. According to the sorption mechanism proposed by Simonnot et al. [16] and as outlined in Scheme 1, high pHs must provide a suitable environment for the sorption of boron by the functional groups like $N$-methylglucamine. As can be seen from Fig. 5, any $\mathrm{pH}>6$ can be used for efficient sorption. The interesting finding here is that the novel sorbent takes up boron from the solution even at a $\mathrm{pH}$ of 6 . This is contradictory to the mechanism proposed in Scheme 1 at which the considered form of boron to be adsorbed is $\mathrm{B}(\mathrm{OH})_{4}{ }^{-}$. The efficient sorption of boron by the new sorbent at a $\mathrm{pH}$ of 6 might be indicative of the presence of an additional sorption mechanism, the validation of which could be a topic of a separate study.

The decrease in sorption at low $\mathrm{pHs}$ was considered as an indication of the acidic solvents to be good candidates for desorption. This was proven in the following section and different acids were used for this purpose.

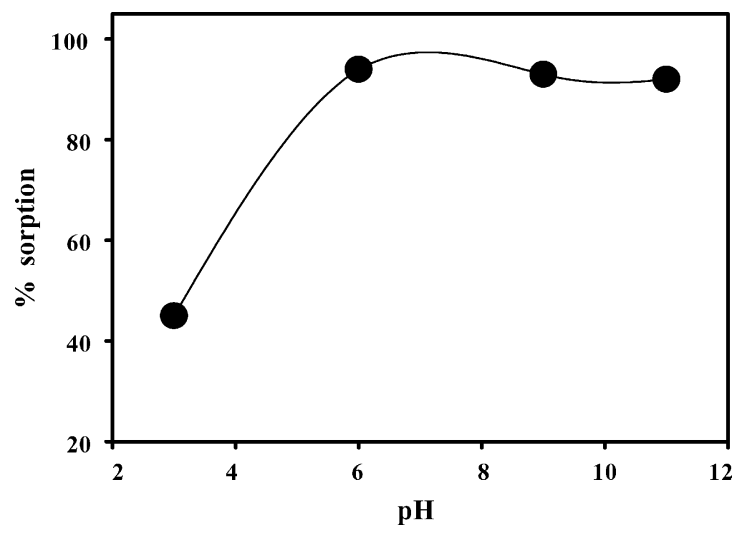

Fig. 5. Boron sorption by NMG-MCM-41(3) as a function of $\mathrm{pH}$. (Solution volume: $20.0 \mathrm{ml}$, sorbent amount: $0.1 \mathrm{~g}$.)

\subsection{Desorption of boron}

The desorption studies of boron from the sorbent NMGMCM-41(3) were carried out with $\mathrm{HNO}_{3}, \mathrm{HCl}$ and $\mathrm{H}_{2} \mathrm{SO}_{4}$ at 1.0 and $2.0 \mathrm{M}$ concentrations. After the usual sorption step with $0.1 \mathrm{~g}$ of the sorbent, the sorbent was put into the acid solution and shaken for $30 \mathrm{~min}$. The solid phase was separated from the mixture by filtration; and to the filtrate was added $\mathrm{NH}_{3}$ and mannitol before ICP-OES measurements. The results showed that the recoveries were either comparable or better with $1.0 \mathrm{M}$ concentration compared to those with $2.0 \mathrm{M}$ for all acids employed. Desorption efficiency in $1.0 \mathrm{M}$ solutions of the acids followed the order $\mathrm{HCl}(83 \pm 3 \%)>\mathrm{HNO}_{3}$ $\left(77 \pm 2 \%>\mathrm{H}_{2} \mathrm{SO}_{4}(66 \pm 2 \%)\right)$.

Although the use of $\mathrm{HCl}$ appeared to be the best choice in desorption process in terms of recovery percentage of boron, it gave rise to a problem in obtaining a stable plasma during nebulization due to the fact that a white deposit (possibly $\mathrm{NH}_{4} \mathrm{Cl}$ ) was being formed in the innermost tube of the ICP-OES torch (through which the sample aerosol is transported). Because of this reason, $\mathrm{HCl}$ was replaced by $\mathrm{HNO}_{3}$ for desorption studies thereafter, as no deposit formation was observed when $1.0 \mathrm{M} \mathrm{HNO}_{3}$ was used.

\subsection{Comparison of the effectiveness of the Amberlite IRA 743 and NMG-MCM-4I(3)}

To understand the efficiency of the synthesized sorbent material in terms of sorption capacity and applicability to the water samples with different matrices, it was compared with the commercial resin Amberlite IRA 743. For this purpose, both aqueous and matrix-matched standard calibration graphs were obtained for Amberlite IRA 743 and NMGMCM-41(3), as shown in Fig. 6. Matrix-matched standards were prepared by applying the proposed sorption/desorption steps to all standard solutions in the calibration graph. Both sample and eluent volumes were $20.0 \mathrm{ml}$. As can

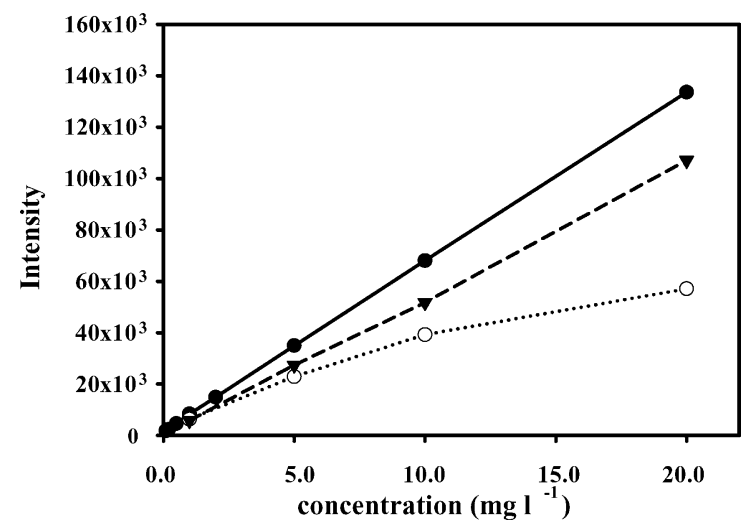

Fig. 6. Calibration graphs for boron. (๑) aqueous standard calibration plot $\left(y=6621.4 x+1436.3, R^{2}=0.9999\right)$, ( $\left.\mathbf{\nabla}\right)$ Amberlite IRA 743 matrixmatched standard calibration plot $\left(y=5310.7 x+178.45, R^{2}=0.9994\right),(\bigcirc)$ NMG-MCM-41(3) matrix-matched standard calibration graph $(y=-98.22$ $\left.x^{2}+4731.4 x+1711.6, R^{2}=1.0000\right)$. 


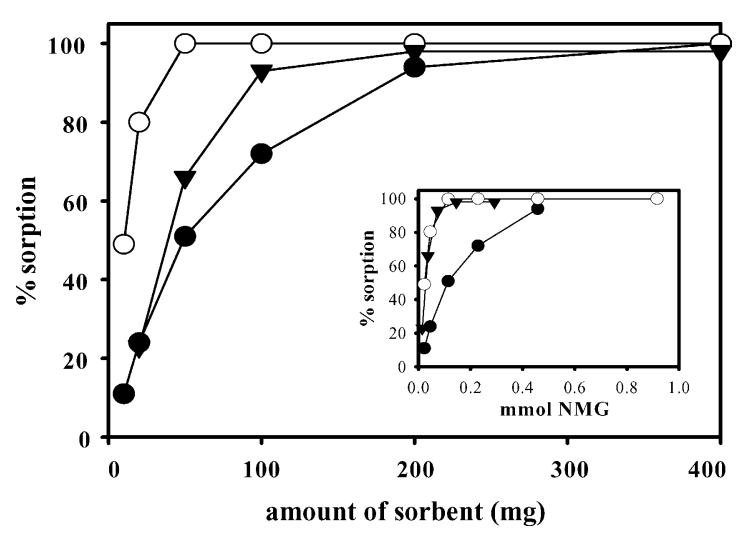

Fig. 7. Comparison of sorption efficiency as a function of sorbent amount, (O) Amberlite IRA 743 (original particle size $(297-1190 \mu \mathrm{m})$ ), (○) Amberlite IRA 743 after grinding (53-75 $\mu \mathrm{m}),(\boldsymbol{\nabla})$ NMG-MCM-41(3). Inset: Percent sorption capacity as a function of mmol of $\mathrm{N}$-methylglucamine (boron concentration: $10.0 \mathrm{mg} \mathrm{l}^{-1}$, solution volume: $20.0 \mathrm{ml}$ ).

be seen from Fig. 6, the sensitivities (slopes) are affected by sorption/desorption steps for both sorbents, however, NMG-MCM-41(3) displayed lower calibration sensitivity as compared to that with Amberlite IRA 743.

Then, the sorption efficiencies of Amberlite IRA 743 and NMG-MCM-41(3) were compared on the basis of both unit mass of the adsorbent and unit molar quantity of glucamine functionality. Clearly, NMG-MCM-41(3) appeared to have higher efficiency for boron sorption on the basis of both parameters when original particle size of Amberlite IRA 743 was considered (Fig. 7). However, upon grinding the Amberlite IRA 743 beads which originally had particle sizes between 297 and $1190 \mu \mathrm{m}$ to yield the particle size range of 53-75 $\mu \mathrm{m}$, its efficiency approached that of NMG-MCM41(3). The enhancement in the efficiency of the commercial resin obtained upon grinding was thought to be due to the increase in the rate of mass transport of sorbates to the interior sorption sites as a result of the particle size reduction.

\subsection{Reusability of sorbents}

Reusability is one of the key parameters to assess the effectiveness of a sorbent. A series of sorption/desorption experiments was performed to understand the reusability of the synthesized NMG-MCM-41(3). After sorption, the sorbent was treated with $1.0 \mathrm{M} \mathrm{HNO}_{3}$ to desorb boron and this sorption/desorption procedure was repeated six times. After each

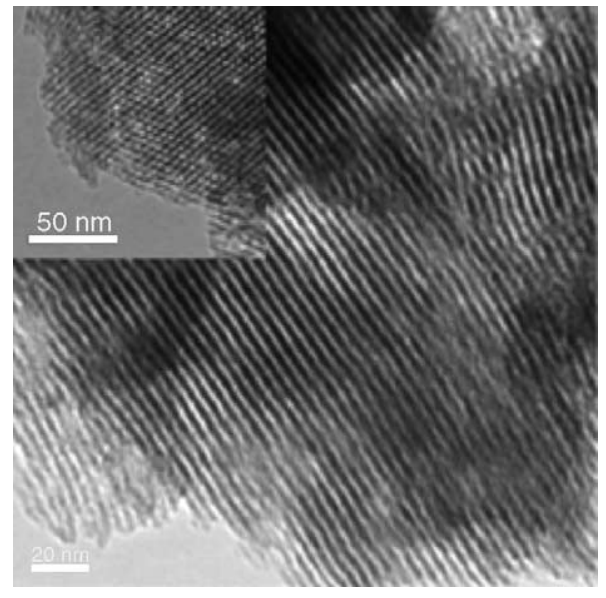

Fig. 8. TEM image of the NMG-MCM-41(3) after six consecutive sorption/elution steps.

desorption step, the sorbent was washed with $0.01 \mathrm{M} \mathrm{NaOH}$ and then with ultra pure water for conditioning. It was determined that there was little decrease in sorption capacity after six consecutive uses of $0.1 \mathrm{~g}$ of material, decreasing from 90 to $82 \%$. SEM microimages showed that the long range morphology of the sorbent were unaltered whereas multiple TEM images recorded at certain locations on the structure indicated a partial decomposition in the order of the hexagonal patterns of the pores of NMG-MCM-41(3) (a typical image is shown in Fig. 8). In the case of Amberlite IRA 743, sorption capacity reduced significantly from 75 to $51 \%$ after six uses when it was applied in original particle size $(297-1190 \mu \mathrm{m})$; while ground Amberlite IRA $743(53-75 \mu \mathrm{m})$ showed little decrease (100-92\%) in its sorption capacity after sixth use.

\subsection{Spike recovery tests}

The performance of the proposed methodology in preconcentrating boron from ultra pure water was also investigated through spike recovery tests at various initial concentration levels between 0.8 and $10.0 \mathrm{mg} \mathrm{l}^{-1}$ (corresponding to initial volumes between 250 and $20.0 \mathrm{ml}$, respectively). The absolute amount of boron was $0.2 \mathrm{mg}$ and the final volume was $20.0 \mathrm{ml}$ in each case. As can be seen from Table 2, with NMG-MCM-41(3), the method can be applied for the determination of boron in ultra pure water at all initial volumes examined, with a slight decrease for an initial volume of

Table 2

Boron recovery results for ultra-pure water with NMG-MCM-41(3) and Amberlite IRA 743 ${ }^{\mathrm{a}}$

\begin{tabular}{|c|c|c|c|c|c|c|}
\hline \multirow[t]{2}{*}{$\mathrm{B}$ spike $\left(\mathrm{mg} \mathrm{l}^{-1}\right)$} & \multirow[t]{2}{*}{ Initial volume (ml) } & \multirow[t]{2}{*}{ Enrichment factor ${ }^{b}$} & \multicolumn{2}{|l|}{ NMG-MCM-41(3) } & \multicolumn{2}{|c|}{ Amberlite IRA $743(53-75 \mu \mathrm{m})$} \\
\hline & & & $\mathrm{B}$ found $\left(\mathrm{mg} \mathrm{l}^{-1}\right)$ & Recovery (\%) & $\mathrm{B}$ found $\left(\mathrm{mg}^{-1}\right)$ & Recovery $(\%)$ \\
\hline 10.0 & 20.0 & 1.0 & $9.5( \pm 0.6)$ & $95( \pm 6)$ & $9.8( \pm 0.1)$ & $98( \pm 1)$ \\
\hline 4.0 & 50.0 & 2.5 & $9.0( \pm 0.3)$ & $90( \pm 3)$ & $9.3( \pm 0.5)$ & $93( \pm 5)$ \\
\hline 2.0 & 100.0 & 5.0 & $8.9( \pm 0.6)$ & $89( \pm 6)$ & $8.9( \pm 0.2)$ & $89( \pm 2)$ \\
\hline 0.8 & 250.0 & 12.5 & $8.3( \pm 1.0)$ & $83( \pm 10)$ & $8.7( \pm 0.3)$ & $87( \pm 3)$ \\
\hline
\end{tabular}

\footnotetext{
a Final volume was $20.0 \mathrm{ml}$ in each case.

b Enrichment factor $=$ initial volume/final volume.
} 
Table 3

Boron recovery results for geothermal water with NMG-MCM-41(3) and Amberlite IRA 743

\begin{tabular}{|c|c|c|c|c|}
\hline \multirow[t]{2}{*}{ B spike $\left(\mathrm{mg} \mathrm{l}^{-1}\right)$} & \multicolumn{2}{|l|}{ NMG-MCM-41(3) } & \multicolumn{2}{|c|}{ Amberlite IRA $743(53-75 \mu \mathrm{m})$} \\
\hline & $\bar{B}$ found $\left(\mathrm{mg} \mathrm{l}^{-1}\right)$ & Recovery (\%) & B found $\left(\mathrm{mg} \mathrm{l}^{-1}\right)$ & Recovery (\%) \\
\hline+0.0 & $7( \pm 0.2)$ & $75( \pm 2)$ & $9( \pm 0.2)$ & $96( \pm 2)$ \\
\hline+5.0 & $12( \pm 0.2)$ & $86( \pm 13)$ & $14( \pm 0.2)$ & $96( \pm 13)$ \\
\hline+10.0 & $19( \pm 0.3)$ & $92( \pm 13)$ & $18( \pm 0.3)$ & $93( \pm 13)$ \\
\hline
\end{tabular}

${ }^{\text {a }}$ Geothermal water had an initial boron concentration of $9.3 \mathrm{mg}^{-1}$. Initial and final volumes were both $20.0 \mathrm{ml}$ in each case.

$250 \mathrm{ml}\left(0.8 \mathrm{mgl}^{-1}\right)$. The very simple matrix of ultra pure water enables high preconcentration factors to be attained. In addition to this experiment, the matrix removal capacity of the method was also investigated through spike recovery tests for geothermal water. In contrast to ultra pure water, geothermal water which is referred to as "heavy-matrix" was expected to complicate the sorption/desorption steps. In these experiments, there was no need for preconcentration and both the initial and the final volumes were $20.0 \mathrm{ml}$. The recovery values as shown in Table 3 (column 3), changed between 75 and $92 \%$ at different spike levels. These recoveries were not very efficient though, yet could be considered as sufficient for many studies containing similar matrices.

A very similar set of experiments was repeated for the commercial resin, Amberlite IRA 743. The results are given in Table 2 (columns 6 and 7) and Table 3 (columns 4 and 5). As expected, the commercial resin worked very efficiently for ultra pure water and adsorbed boron at all concentrations studied. When the spike recovery results for geothermal water are considered, it can be said that the sorption capacities of NMG-MCM-41(3) and Amberlite IRA 743 are similar and efficient.

\subsection{Boron sorption kinetics}

Kinetic behaviour of the sorbent NMG-MCM-41(3) was examined by monitoring the percent sorption with respect to the shaking time. For this purpose, $0.1 \mathrm{mg}$ of the sorbent was added into $20.0 \mathrm{ml}$ of $10.0 \mathrm{mg} \mathrm{l}^{-1}$ boron for different periods of time. The sorption rate for boron was rapid; an interaction period of $1 \mathrm{~min}$ supplied $75 \%$ sorption whereas the equilibrium was reached after $30 \mathrm{~min}$ (Fig. 9).

Lagergren's equation [49], developed as a pseudo first order kinetics, was applied to fit the kinetic data of the NMGMCM-41(3) (inset of Fig. 9). The equation is given by:

$\ln \left(1-\frac{[\mathrm{C}]_{\mathrm{t}}}{[\mathrm{C}]_{\mathrm{e}}}\right)=-k_{\mathrm{a}} t$

where $k_{\mathrm{a}}$ apparent rate constant; $[\mathrm{C}]_{\mathrm{t}}$ the concentration on the solid phase at any time; $[\mathrm{C}]_{\mathrm{e}}$ the concentration on the solid phase at equilibrium.

The linear square fits of the equation gave the rate constant as $0.051 \mathrm{~min}^{-1}$, a value indicating that sorption proceeds with fast kinetic steps.

\subsection{Determination of sorption isotherms}

The sorption experiments of boron were performed in the batch mode. The equilibrium relationship between the amount of boron adsorbed per unit mass of the sorbent NMGMCM-41(3) ([C] $\left.]_{\mathrm{s}}\right)$ and the residual boron concentration in solution phase $\left([\mathrm{C}]_{1}\right)$ were expressed by adsorption isotherms. The uptake of boron was studied in the concentration range $5.0-200.0 \mathrm{mg} \mathrm{l}^{-1}$ while the amount of solid in each solution was held constant at $0.1 \mathrm{~g}$. The applicability of the Freundlich and Dubinin-Radushkevich (D-R) sorption isotherms were tested under these specified conditions. The general expression of Freundlich Isotherm is given as:

$[\mathrm{C}]_{\mathrm{S}}=k \cdot[\mathrm{C}]_{1}{ }^{n}$

where $[\mathrm{C}]_{\mathrm{s}}$ the concentration on the solid phase, $\mathrm{mmol} \mathrm{g}^{-1}$; $[\mathrm{C}]_{\mathrm{I}}$ the concentration in the liquid phase, $\mathrm{mmol}^{-1} ; \mathrm{k}$ a constant related to sorption capacity, $\mathrm{mmolg}^{-1} ; n$ a constant related to linearity of the sorption curve.

This expression can be linearized as:

$\log [\mathrm{C}]_{\mathrm{S}}=\log k+n \log [\mathrm{C}]_{1}$

The linear plots of $\log [\mathrm{C}]_{\mathrm{S}}$ versus $\log [\mathrm{C}]_{1}$ show that the sorption data obeys the Freundlich isotherm model. The slope and intercept in the linear fits give the coefficients, $n$ and $k$, respectively.

Freundlich isotherm model allows for several kinds of adsorption sites on the solid, each kind having a different heat of adsorption. The Freundlich isotherm represents well the data

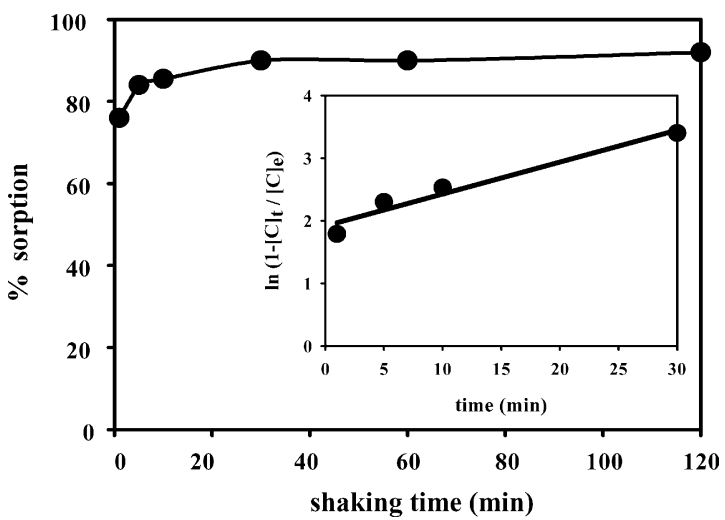

Fig. 9. Boron sorption on NMG-MCM-41(3) as a function of shaking time. Inset: Kinetic behaviour of NMG-MCM-41(3) based on Lagergren's equation. $\left(y=0.051 x+1.9182, R^{2}=0.9551\right)$. 
at low and intermediate concentrations and is a good model for heterogenous surfaces. When the value of Freundlich constant $n$ is equal to unity, Freundlich equation becomes linear and the Freundlich constant $k$ becomes equivalent to the distribution ratio, $R_{\mathrm{d}}$, which is an empirical constant usually used in the quantification of the sorption process [50].

The values of Freundlich constants, $\mathrm{n}$ and $\mathrm{k}$, obtained from the linear fits of our data were respectively, 0.26 and $0.32 \mathrm{mmol} \mathrm{g}^{-1}$. As implied by the value of $n$, sorption seems to be highly nonlinear, the thing that indicates a fast decrease in the fixation capacity of the sorbent sites as the initial concentration is increased. Since Freundlich isotherm does not predict a maximum coverage for a given sorbent, it is hard to say that $k$ corresponds to the maximum sorption capacity. The value of $k$ can, however, be correlated with the sorption capacity of the sorbent under the particular experimental conditions and can be useful in providing a qualitative comparison for the fixation ability of a given sorbent towards different sorbates.

$\mathrm{D}-\mathrm{R}$ isotherm model is applicable at low concentration ranges and can be used to describe sorption on both homogeneous and heterogeneous surfaces. It can be represented by the general expression:

$[\mathrm{C}]_{\mathrm{s}}=C_{\mathrm{m}} \exp -\left(K \varepsilon^{2}\right)$

When the logarithm of the $\mathrm{D}-\mathrm{R}$ equation is taken,

$\ln [\mathrm{C}]_{\mathrm{s}}=\ln C_{\mathrm{m}}-K \varepsilon^{2}$

where $\varepsilon=R T \ln \left(1+1 /[\mathrm{C}]_{1}\right) ;[\mathrm{C}]_{\mathrm{s}}$ the concentration on the solid phase, $\mathrm{mmolg}^{-1} ;[\mathrm{C}]_{\mathrm{I}}$ the concentration in the liquid phase, $\mathrm{mmoll}^{-1} ; C_{\mathrm{m}}$ the maximum amount of B that can be sorbed by the sorbent, $\mathrm{mmol} \mathrm{g}^{-1} ; \mathrm{K}$ a constant related to sorption energy.

The linear curves of $\ln [\mathrm{C}]_{\mathrm{s}}$ versus $\varepsilon^{2}$ showed that sorption obeys D-R sorption isotherm model. The slope of the linear fits gives the logarithm of $C_{\mathrm{m}}$ and the intercept gives the coefficient $K$ which is related to the sorption energy $\left(E=(-2 K)^{-1 / 2}\right)$. The sorption energy, $E$, can be defined as the energy $\left(\mathrm{kJ} \mathrm{mol}^{-1}\right)$ required to transfer $1 \mathrm{~mol}$ of sorbate species to the surface of the sorbent from infinity in the bulk of the solution [50]. Utilizing $K$, the sorption energy value was calculated as $11.5 \mathrm{~kJ} \mathrm{~mol}^{-1}$. The energy changes for chemisorption are usually substantially greater in magnitude than those for physical adsorption. Typically, energies for chemisorption lie in the range -40 to $-800 \mathrm{~kJ} \mathrm{~mol}^{-1}$, whereas those for physical adsorption range usually from -4 to $-40 \mathrm{~kJ} \mathrm{~mol}^{-1}$. [51]. Based on the value of $C_{\mathrm{m}}$, the maximum amount of boron (as boric acid) that can be sorbed by the sorbent is estimated to be $0.8 \mathrm{mmol} \mathrm{g}^{-1}$ of the sorbent.

\section{Conclusion}

Synthesis of a new sorbent through the functionalization of MCM-41 with $N$-methylglucamine has been described and shown to be an alternative and efficient route for re- moval/preconcentration purposes in the determination of B in various water samples. Characterization of the novel sorbent was realized with the use of BET, XRD, TEM, SEM and DRIFTS techniques, in addition to its $\mathrm{C}$ and $\mathrm{N}$ elemental content. After synthesis and characterization experiments, optimum application conditions were investigated and it was found that $0.1 \mathrm{~g}$ of the sorbent was sufficient for $20.0 \mathrm{ml}$ of the sample solution containing $10.0 \mathrm{mg}^{-1}$. The kinetic studies have shown that the sorbent can take up $85 \%$ of boron from solution in $5 \mathrm{~min}$ whereas $30 \mathrm{~min}$ was required for quantitative sorption. To investigate the sorption mechanism and maximum amount of boron that can be sorbed by the sorbent, Freundlich and Dubinin-Radushkevich sorption isotherms were applied. According to the results of the isotherms, there exist heterogeneous sites for sorption for low and high concentration levels, and $0.8 \mathrm{mmol}$ of boron $\left(\mathrm{as}_{3} \mathrm{BO}_{3}\right)$ can be retarded from the solution per gram of sorbent. Efficient sorption takes place at a $\mathrm{pH}$ higher than 6 and desorption of the sorbed boron from the sorbent can be realized with $1.0 \mathrm{M} \mathrm{HNO}_{3}$.

The sorption efficiency of the new sorbent was also compared to and found to be better than that of Amberlite IRA 743 (a commercial resin with $N$-methylglucamine functional groups which is frequently used for boron removal in environmental waters) within the employed experimental conditions. Applicability of the novel sorbent to a real sample, geothermal water, was also demonstrated through spike recovery tests; a topic which requires further studies.

\section{Acknowledgements}

We would like to acknowledge İzmir Institute of Technology for support of this work through the fund 2002 IYTE 34, the Center for Materials Research for the facilities (XRD and SEM-EDX). We also thank Res. Sci. Oya Altungöz for ICP-OES measurements and Dr. Fehime Özkan for her help in evaluating BET analysis results.

\section{References}

[1] D. Darbouret, I. Kano, J. Anal. Atom. Spectrom. 15 (2000) 1395.

[2] European Centre for Ecotoxicology and Toxicology of Chemicals, Special Report, No. 11.

[3] B. Welz, M. Sperling, 3rd ed., Wiley VCH, Weinheim, 1999.

[4] N.R. Sah, P.H. Brown, Microchem. J. 56 (1997) 285.

[5] M. Burguera, J.L. Burguera, C. Rondón, P. Carrero, Spectrochim. Acta B 56 (2001) 1845.

[6] D.A. Johnson, D.D. Siemer, W.F. Bauer, Anal. Chim. Acta 270 (1992) 223

[7] T.U. Prost, N.G. Berryman, P. Lemmen, L. Weissfloch, T. Auberger, D. Gabel, J. Carlsson, B. Larson, J. Anal. Atom. Spectrom. 12 (1997) 1115.

[8] D.H. Sun, J.W. Waters, T.P. Mawhinney, J. Anal. Atom. Spectrom. 12 (1997) 675.

[9] R. Kunin, A.F. Preuss, Ind. Eng. Chem. 3 (1964) 304.

[10] U. Schilde, E.U. Hlemann, React. Polym. 18 (1992) 155.

[11] W.R. Lyman, A.F. Preus, U.S. Patent, No. 2,813,838 (Rohm\&Hass Company) (1957). 
[12] S. Sahin, ACH: Models Chem. 133 (1996) 143.

[13] O. Okay, H. Güçlü, E. Soner, T. Balkas, Water Res. 19 (1985) 857.

[14] O. Recepoglu, U. Beker, Geothermics 20 (1991) 83.

[15] N. Kabay, I. Yılmaz, S. Yamac, S. Samatya, M. Yuksel, U. Yuksel, M. Arda, M. Saglam, T. Iwanaga, K. Hirowatari, React. Funct. Polym. 60 (2004) 163.

[16] M.O. Simonnot, C. Castel, M. Nicolai, C. Rosin, M. Sardin, H. Jauffret, Water Res. 34 (2000) 109.

[17] N. Bicak, N. Bulutcu, B.F. Senkal, M. Gazi, React. Funct. Polym. 47 (2001) 175.

[18] Y. Inukai, Y. Tanaka, T. Matsuda, N. Mihara, K. Yamada, N. Nambu, O. Itoh, T. Doi, Y. Kaida, S. Yasuda, Anal. Chim. Acta 511 (2004) 261.

[19] A.R. Cestari, E.F.S. Vieira, J.A. Simoni, C. Airoldi, Thermochim. Acta 348 (2000) 25

[20] F.S. Vieira, A.R. Cestari, J.A. Simoni, C. Airoldi, Thermochim. Acta 328 (1999) 247.

[21] A.W. Flounders, D.L. Brandon, A.H. Bates, Appl. Biochem. Biotech. 50 (1995) 265.

[22] S.W. Park, Y.I. Kim, K.H. Chung, S.I. Hong, S.W. Kim, React. Funct. Polym. 51 (2002) 79.

[23] E.F. Vansant, P. Van der Voort, K.C. Vrancken, Characterisation and Chemical Modification of the Silica Surface, Elsevier, The Netherlands, 1995.

[24] C.T. Kresge, M.E. Leonowicz, W.J. Roth, J.C. Vartuli, J.S. Beck, Nature 359 (1992) 710.

[25] J.S. Beck, J.C. Vartuli, W.J. Roth, M.E. Leonowicz, C.T. Kresge, K.D. Schmitt, C.T.W. Chu, D.H. Olsen, E.W. Sheppard, S.B. McCullen, J.B. Higgins, J.L.A. Schlenker, J. Am. Chem. Soc. 114 (1992) 10835.

[26] K. Moller, T. Bein, Chem. Mater. 10 (1998) 2950.

[27] L. Mercier, T.J. Pinnavaia, Adv. Mater. 9 (1997) 500.

[28] D. Brunel, A. Cauvel, F. Fajula, F. Di Renzo, Stud. Surf. Sci. Catal. 97 (1995) 73.

[29] P. Sutra, D. Brunel, Chem. Commun. (1996) 2485.

[30] X. Feng, G.E. Fryxell, L.Q. Wang, A.Y. Kim, J. Liu, K.M. Kemner, Science 276 (1997) 923.
[31] D.S. Shepard, W. Zhou, T. Mashmeyer, J.M. Matters, C.L. Roper, S. Parsons, B.F.G. Johnson, M.J. Duer, Angew. Chem., Int. Ed. Engl. 37 (1998) 2719.

[32] M.H. Lim, A. Stein, Chem. Mater. 11 (1999) 3285.

[33] M.C. Burleigh, M.A. Markowitz, M.S. Spector, B.P. Gaber, Chem. Mater. 13 (2001) 4760.

[34] S.L. Burkett, S.D. Sims, S. Mann, Chem. Commun. (1996) 1367.

[35] M.H. Lim, C.F. Blanford, A. Stein, J. Am. Chem. Soc. 119 (1997) 4090.

[36] J.F. Diaz, K.J. Balkus, F. Bedioui, V. Kurshev, L. Kevan, Chem. Mater. 9 (1997) 61

[37] S.Y.V. Rao, D.E. De Vos, P.A. Jacobs, Angew Chem., Int. Ed. Engl. 36 (1997) 2661.

[38] M.H. Lim, C.F. Blanford, A. Stein, Chem. Mater. 10 (1998) 467.

[39] A. Bibby, L. Mercier, Chem. Mater. 14 (2002) 1591.

[40] A. Walcarius, M. Etienne, B. Lebeau, Chem. Mater 15 (2003) 2161.

[41] D.H. Sun, R.L. Ma, C.W. Mcleod, X.R. Wang, A.G. Cox, J. Anal. Atom. Spectrom. 14 (2000) 257.

[42] H.P. Lin, S. Cheng, C.Y. Mou, Micropor. Mater. 10 (1997) 111.

[43] B. Marler, U. Oberhagemann, S. Vortmann, H. Gies, Micropor. Matter 6 (1996) 375.

[44] M.V. Landau, S.P. Varkey, M. Herskowitz, O. Regev, S. Pevzner, T. Sen, Z. Luz, Micropor. Mesopor. Mater. 33 (1999) 149.

[45] K.A. Koyano, T. Tatsumi, J. Phys. Chem. B 101 (1997) 9436.

[46] J.M. Kisler, M.L. Gee, G.W. Stevens, A.J. O'Connor, Chem. Mater. 15 (2003) 619.

[47] H. Yang, G. Zhang, X. Hong, Y. Zhu, Micropor. Mesopor. Mater. 68 (2004) 119.

[48] The stability of the silylated MCM-41 is under investigation for basic reagents both in water and non-aqueous solutions. The study on this issue is under investigation and to be presented elsewhere in due course.

[49] D.C. Liu, C.N. Hsu, C.C. Chuang, Appl. Radiat. Isot. 46 (1995) 839.

[50] T. Shahwan, H.N. Erten, J. Radioanal. Nucl. Chem. 241 (1999) 151.

[51] I.N. Levine, Physical Chemistry, 3rd ed., McGraw-Hill Book Company, Singapore, 1988. 